\title{
CONTEÚDOS MATEMÁTICOS: PROPOSTAS COM A APLICAÇÃO DO SCRATCH
}

\author{
Marcos Mincov Tenório, Cristiane Budek Dias, Jorge José Kleinubing, \\ STEFANE LAYANA GAFFURI, GuataÇARA dos SANTOS JR \\ Universidade Tecnológica Federal do Paraná \\ <marcostenorio@utfpr.edu.br>. <crisbudek@hotmail.com>. <kleinubing@alunos.utfpr.edu.br>. \\ <stefanegaffuri@utfpr.edu.br>, <guata@utfpr.edu.br>
}

DOI: 10.21439/conexoes.v10i4.1105

\begin{abstract}
Resumo. O uso das tecnologias na Educação Matemática apresenta uma abordagem na busca por uma Matemática significativa e relacionada à realidade do aluno, possibilitando a construção do conhecimento, a comunicação matemática e a resolução de problemas. Aplicativos computacionais educacionais surgiram oportunizando aos alunos a aplicação dos conceitos matemáticos bem como aproximações com linguagens de programação. Um exemplo destes aplicativos é o Scratch. O presente artigo traz uma compilação bibliográfica com objetivo de auxiliar professores no entendimento da ferramenta Scratch e suas finalidades, bem como identificar diferentes conteúdos que podem ser trabalhados em sala de aula por meio dela como atividade prática, considerando os anos finais do Ensino Fundamental e os Conteúdos Estruturantes dispostos nas Diretrizes Curriculares Estaduais do Estado do Paraná. Para a concretização deste estudo, foi realizado um levantamento dos conteúdos matemáticos a serem trabalhados nos anos finais do Ensino Fundamental, bem como a identificação de quais conteúdos podem ser ensinados através do Scratch. Percebeu-se que o Scratch é uma importante ferramenta que pode ser amplamente explorada no processo de ensino e aprendizagem da Matemática, entretanto é importante que haja um entendimento a respeito dos conteúdos e das formas de aplicação prática no software.
\end{abstract}

Palavras-chaves: Ensino de Matemática. TIC no Ensino. Scratch

\begin{abstract}
The use of technologies on Mathematic Education presents an approach on a meaningful and significant teaching of mathematics enabling the knowledge construction, mathematical communication and problem solving. Educational software emerged providing to students proximity to mathematical concepts and programming languages. Scratch is one of these softwares. This paper presents a bibliographic compilation in order to assist teachers to understand the Scratch tool and its purpose, identifying different contents that can be introduced in classes through practical activities, considering the final years of elementary school and structuring contents arranged in the Curriculum Guidelines of Paraná State, Brazil. To achieve these goals, we held an research of the mathematical content to be worked out in the final years of elementary school, then identifying witch content can be taught through Scratch. It was noticed that Scratch is an important tool that can be widely exploited in the teaching and learning of mathematics, however it is important to have an understanding about the contents and forms of practical application in software.
\end{abstract}

Keywords: Mathematic teaching. ICT in Education. Scratch

\section{INTRODUÇÃO}

Nas últimas décadas as discussões sobre o processo de ensino e aprendizagem da Matemática têm se intensificado, especialmente aquelas que buscam a superação de um ensino marcadamente tradicional que ainda impera em muitas das práticas docentes. Nesse sentido, algumas tendências surgiram e outras foram aprimoradas.

Dentre essas tendências tem-se o uso das Tecnologias de Informação e Comunicação (TIC) que têm sido motivado pelo surgimento de novas tecnologias digitais e pela familiaridade das novas gerações com as 
mesmas. Uma vez que tecnologias digitais já fazem parte do cotidiano das novas gerações, há possibilidade de sua aplicação no Ensino da Matemática, tornando-o mais significativo e próximo à realidade do aluno, possibilitando a construção do conhecimento, a comunicação matemática e a resolução de problemas.

Embora muitos aplicativos computacionais educacionais surjam apontando para novos rumos, em que a construção do conhecimento é priorizada, a maioria deles apenas substitui formatos tradicionais. Nestes casos, o que se altera é apenas o recurso utilizado, uma aplicação computacional, um computador, um celular e essa não é a aplicação correta das TIC pois não há a superação do tradicionalismo. Para a correta aplicação das TIC é necessário que o aluno, ao se deparar com situações problemas, consiga utilizar conhecimentos matemáticos e resolvê-los por meio de recursos tecnológicos. Assim, as TIC estarão proporcionando, não um fim, mas um meio para essa resolução. Para isto, são necessários aplicativos construídos com esta finalidade.

Papert (2008) defende tal ideia e afirma que o aluno é um construtor de seu conhecimento, logo deve-se oferecer matéria, ou ferramentas, ao construtor. Papert ainda propõe uma linguagem denominada Logo para que sirva como ferramenta ao construtor. Algum tempo depois esta linguagem é aprimorada e então resulta no programa denominado Scratch.

Em pouco tempo o Scratch tornou-se uma importante ferramenta que pode ser amplamente explorada no processo de ensino e aprendizagem da Matemática. Além de sua aproximação com conceitos matemáticos os alunos também têm um primeiro contato com a computação, entendendo o que é a programação computacional. Entretanto é importante que o docente seja direcionado para melhor explorar a ferramenta com os alunos ao invés de apenas transferir o ensino tradicional para uma ferramenta computacional. Além disto, não são todos os conteúdos matemáticos que podem ser exercitados com o Scratch. É preciso conhecer quais conteúdos podem ser abordados por meio de aplicações práticas no Scratch.

Dessa forma, este estudo busca auxiliar professores no correto entendimento da ferramenta Scratch e suas finalidades, bem como identificar diferentes conteúdos que podem ser trabalhados em sala de aula por meio dela como atividade prática, considerando os anos finais do Ensino Fundamental e os Conteúdos Estruturantes dispostos nas Diretrizes Curriculares Estaduais do estado do Paraná (PARANÁ, 2008, p.48).

\section{TIC NO ENSINO}

A discussão sobre o uso da tecnologia no processo formal de ensino não é algo recente. A partir da popularização dos computadores essa discussão se intensifica, permitindo que novas ideias e ferramentas sejam criadas e aprimoradas.

Para Borba, Silva e Gadanidis (2014), na década de 90 do século passado, com a acessibilidade e a popularização dos computadores, as pessoas passam a pensar no uso do computador em suas vidas pessoais e profissionais, trazendo mais perspectivas para o uso desse instrumento na educação. "Diversos softwares educacionais foram então produzidos, por empresas, governos e pesquisadores. Professores passaram a encontrar, em cursos de formação continuada, suporte e alternativas para que TI fossem utilizadas em suas aula" (BORBA; SILVA; GADANIDIS, 2014, p. 22).

No ensino, o uso das Tecnologias de Informação e Comunicação (TIC) consistem em suportes para facilitar o processo de ensino e aprendizagem, e muitos estudos científicos, desde a década de 90, defendem suas potencialidades para aplicações nesse processo, como pode-se observar em Ponte (1991, p. 67):

\footnotetext{
Um único computador na escola pode significar, só por si, a criação de uma grande dinâmica, se houver imaginação e iniciativa para o tornar acessível aos alunos. $\mathrm{O}$ professor pode contar com a colaboração destes para se ajudarem uns aos outros, para fazerem cursos de programação ou de iniciação ao uso de programas utilitários e para envolverem múltiplas iniciativas envolvendo toda a escola.
}

O autor ainda apresenta que a influência das TIC são favoráveis a diversas áreas do ensino, especialmente no ensino da Matemática. Esta perspectiva quebra alguns dos métodos de ensino tradicionais baseados na repetição e, longe da realidade do estudante. "A construção de conceitos matemáticos utilizando o computador como recurso e um software de programação como um meio, proporciona uma rica experiência no processo de assimilação do conhecimento e na formação de habilidades dos alunos" (VENTORINI; FIOREZE, 2014). Deste modo, o computador pode ser entendido como motivador de aprendizagens significativas, isso porque traz a possibilidade de articulação com situações cotidianas (PINTO, 2011).

Embora o computador possa ser um aliado poderoso para a transformação do processo de ensino e aprendizagem, não basta apenas computadorizar o ensino tradicional. É necessário que o computador proporcione aos alunos oportunidades na construção de seu conheci- 
CONTEÚDOS MATEMÁTICOS: PROPOSTAS COM A APLICAÇÃO DO SCRATCH

mento, como pode-se verificar na teoria construcionista defendida por Papert.

\subsection{A Teoria Construcionista}

A teoria construcionista surgiu com Papert, um dos defensores da aplicação do computador no ensino. Chamou a abordagem de construcionista, pois o estudante constrói, por intermédio do computador, o seu próprio conhecimento. Desta forma, se olha a criança como um construtor, para isto é necessário oferecer matéria ao construtor. Papert também desenvolveu a linguagem Logo, para que, juntamente com o computador seja a matéria na qual o aluno utiliza-se para realizar a construção (VALENTE, 1993).

Pinto 2011, p. 28-29) afirma que, para "Papert, o construcionismo baseia-se no pressuposto de que será melhor para as crianças encontrar por si mesmos os conhecimentos específicos que necessitam, vendo assim os seus esforços recompensados moral, psicológica, material e intelectualmente". Papert dá ênfase ao sentido pessoal da construção, o que possibilita ao aluno imaginar, fantasiar, usar a criatividade e o intelecto (PAPERT, 2008). Dessa forma, "o computador, ao ser manipulado pelo indivíduo, na visão construcionista de Papert, permite a construção e reconstrução do conhecimento, e a aprendizagem torna-se uma descoberta" (MARTINS, 2012, p. 37).

Papert (2008), ainda afirma que a escolha daquilo que se que pretende desenvolver como atividade, é condição indispensável para o sucesso da aprendizagem, pois é preciso considerar que propostas que pareçam significativas para um aluno podem não ter o mesmo significado para outro. "Nestas situações a solução é complexa, uma vez que o ambiente de aprendizagem pode funcionar numa lógica de dualidade, se para uns alunos deve permitir um alto nível de liberdade, para outros é necessário fornecer pistas e sugestões de possíveis projetos" (PINTO, 2011). Isto depende da capacidade na qual o professor monitora as situações de acordo com os alunos (PAPERT, 2008).

Além do citado, ainda existem diversas questões que devem ser consideradas no desenvolvimento de um ambiente de aprendizagem. Mas deve-se ter muita atenção ao projeto pedagógico, pois este precisa ser sólido e adequado em conteúdo e em propostas educacionais.

Ainda assim, tais ambientes são bem aceitos pelos alunos, uma vez que os novos recursos tecnológicos já fazem parte de seus cotidianos. Dessa forma, ambientes que utilizam o computador, como a linguagem Logo, podem ser considerados ricos para a abordagem numa perspectiva construcionista, como afirma Papert (2008).

\subsection{Educação Matemática, Resolução de Proble- mas e Tecnologias}

O ensino de Matemática nas escolas vem, ao longo dos anos, assumindo novas posturas, visto que, nos dias de hoje, já não faz mais sentido um conhecimento matemático desvinculado do contexto do aluno e, também, da sociedade. Nas Diretrizes Curriculares Estaduais paranaenses é evidente a opção pela Educação Matemática, em que deve-se buscar por um ensino que oportunize "análises, discussões, conjecturas, apropriação de conceitos e formulação de ideias" (PARANÁ, 2008, p. 48). A aprendizagem da Matemática, então, passa a ser mais uma oportunidade de ampliação do conhecimento e uma consequente forma de desenvolver a sociedade (PARANÁ, 2008).

Os conhecimentos matemáticos precisam ser encarados como aporte para a reflexão e para a resolução de muitos dos problemas enfrentados pela sociedade dos dias atuais. Em decorrência disso, a prática docente em Matemática deve considerar o tratamento dos conteúdos por meio das tendências da Educação Matemática, como a resolução de problemas; a modelagem; as tecnologias; a etnomatemática; a história da Matemática e as investigações matemáticas. Essas tendências se completam e podem ser trabalhadas conjuntamente (PARANÁ, 2008).

Nesse contexto, tem-se por pressuposto que a resolução de problemas e as tecnologias são tendências que podem ser trabalhadas conjuntamente, trazendo possibilidades singulares para que a Matemática possa ser encarada de forma menos determinística.

A resolução de problemas é essencial na aprendizagem matemática, pois possibilita o envolvimento em tarefas em que os métodos de solução não são conhecidos de imediato e, para, se chegar à solução, é preciso a aplicação de conhecimentos matemáticos. (ROMANATTO, 2012). Nesse ínterim, "Solucionar problemas não é apenas buscar aprender Matemática e, sim, fazêla" (ROMANATTO, 2012, p. 302). De acordo com as Diretrizes Curriculares do Estado do Paraná (2008) as formas de resolução de problemas podem ser potencializadas com o uso de recursos tecnológicos. De acordo com o documento o "trabalho com as mídias tecnológicas insere diversas formas de ensinar e aprender, e valoriza o processo de produção de conhecimentos" (PARANÁ, 2008, p. 66).

As TIC surgem uma vez que recursos tecnológicos são cada vez mais utilizados pelos estudantes, e na medida em que se desenvolve, professores de matemática se deparam com a necessidade de buscar novas opções de trabalho com os alunos (BORBA; PENTEADO, 2001). Assim, a integração das TIC no trabalho 
com a Matemática é fundamental para que o processo de ensino e aprendizagem dos dias de hoje venha ao encontro das reais necessidades dos estudantes e também para que esse processo seja facilitado.

Os Parâmetros Curriculares Nacionais de Matemática também trazem colocações importantes nesse sentido, assinalando que "As tecnologias, em suas diferentes formas e usos, constituem um dos principais agentes de transformação da sociedade, pelas modificações que exercem no cotidiano das pessoas" (BRASIL, 2001).

As TIC estão presentes nas diversas práticas sociais, aprimorando a resolução de alguns problemas enfrentados pela humanidade, tornando mais eficazes os processos produtivos, estreitando relações e diminuindo o espaço geográfico entre as pessoas. Isso faz com que a inserção das TIC seja justificada e ampliada para os mais diferentes contextos, como no processo educativo.

Os PCN ainda apontam que pesquisadores desse tema:

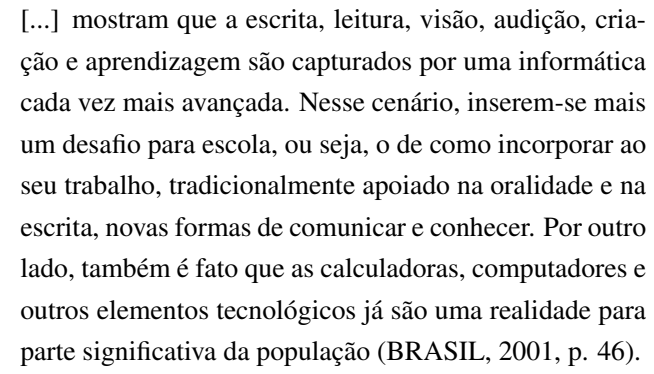

O uso desses recursos traz significativas contribuições para se refletir sobre o processo de ensino e aprendizagem de Matemática e para uma abordagem fundamentada na resolução de problemas, em que a experimentação e a construção sejam permitidas aos estudantes.

É preciso considerar, portanto, tanto o processo criativo como as estratégias que os alunos dispendem na resolução dos problemas levantados em sala de aula. "A resolução de um problema só ocorre quando um indivíduo se confronta com um problema, decide resolvê-lo pelos seus próprios meios e, portanto, aplica procedimentos que não estão à priori estabelecidos ou não são à priori conhecidos" (PALHARES, 1997, p. 167).

Destarte se confirma a necessidade de que novas formas de entender e promover a resolução de problemas no ensino de Matemática sejam consideradas no processo educativo e, nessa perspectiva, as ferramentas computacionais podem ser facilitadoras no processo de ensino e aprendizagem, pois podem substancializar o conhecimento. Na interação da criança com o computador, por meio da lógica de programação, a mesma, "consegue aprender relações matemáticas pela experiência e constrói seu próprio caminho" (MARCON et al. 2012, p. 02).

É nesse sentido que se propõe o uso do Scratch, para que situações mais desafiadoras possam ser proporcionadas aos estudantes. Em momentos em que os mesmos poderão exercitar a criatividade, o pensamento e raciocínio lógico. O que poderá contribuir tanto para a aprendizagem dos conceitos matemáticos como para a motivação e desmistificação de que a Matemática é difícil e enfadonha.

\section{SCRATCH}

O Scratch é um programa de computador (software), mas seu nome também representa seu personagem (seu símbolo) e sua linguagem gráfica de programação, inspirada no Logo. Através do Scratch é possível criar histórias interativas, fazer animações, simulações, jogos e músicas. Há também um ambiente virtual no qual todas as criações podem ser compartilhadas na Internet. O Scratch surgiu em 2007, através do projeto Lifelong Kindergarten coordenado por Mitchel Resnick do MIT Media Lab (Massachusetts Institute of Technology).

Algumas das potencialidades são: liberdade de criação, criatividade; comunicação e compartilhamento; aprendizagem de conceitos escolares, partindo de projetos livres e não escolarizados; manipulação de multimídia; compartilhamento e colaboração através da Internet, que permite abrir projetos de outros, reutilizar, adaptar e divulgar as criações; integração de objetos do mundo físico (SCRATCH, 2017).

A programação no Scratch é realizada através de arrastar e soltar blocos de construção. A medida que são soltos, ou posicionados, os blocos formam pilhas ordenadas. Estas pilhas são as sequências lógicas, ou ordens que o programa seguirá. Os blocos são concebidos para se encaixar de modo que não haja erros de sintaxe. A Figura 1 apresenta a tela inicial do programa e os componentes para realização do código.

Para a programação, existem as categorias de comandos (Figura 1 - 1), dentro de cada categoria, separada por cor, existem os blocos de comandos (Figura 1 - 2). Para inserir os comandos o usuário arrasta e solta o bloco no painel de comandos (Figura 1-3), ao finalizar os comandos se observa o resultado do código no palco (Figura 1-4). Há também outras possibilidades de objetos e personagens que podem ser programados e podem ser encontrados na seção dos sprites (Figura 1 - 5). Normalmente o Scratch (personagem) é utilizado por padrão nas primeiras animações.

Toda a programação, ou seja, sua linguagem são os blocos de construção. Existem algumas categorias e 


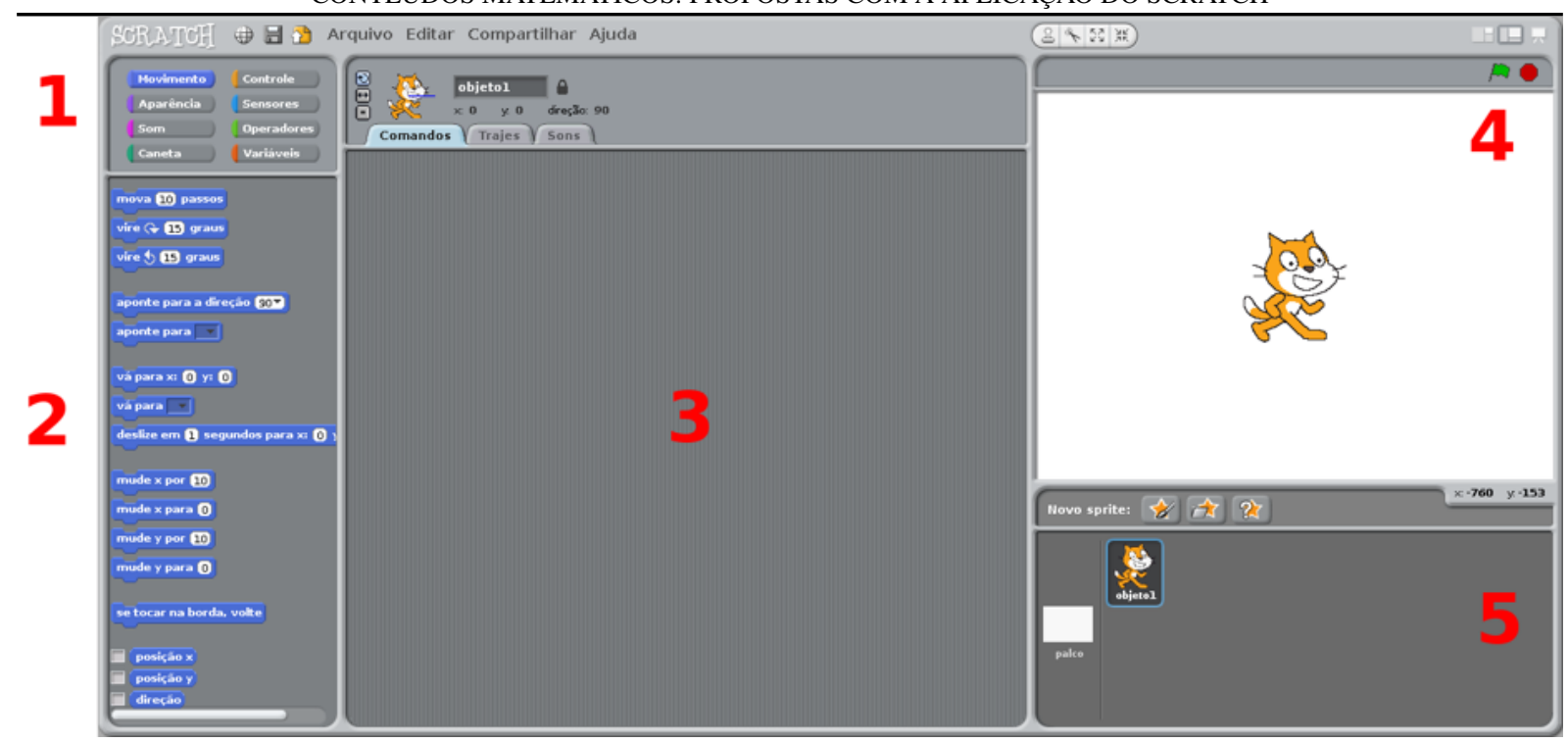

Figura 1: Tela inicial do Scratch. Fonte: (SCRATCH 2017)

blocos que são mais comumente utilizadas. A Figura 2 apresenta alguns comandos (blocos de construção) e um exemplo de utilização cuja finalidade é movimentar o personagem na tela.

Observe através da Figura 2 -b que há uma sequência de passos que podem contar uma história sobre como o programa funciona. A partir deste exemplo é possível observar que há inúmeros conceitos sendo trabalhados a medida em que o aluno utiliza os blocos para construção, como estruturas de repetição (loops), estruturas de condição, movimento, tempo, entre outros.

A forma de programação do Scratch assemelha-se a forma procedural de programação utilizada em diversas linguagens de programação. Logo, quando o aluno compreende a linguagem do Scratch, é possível afirmar que este aluno apresenta facilidades para dominar uma linguagem de programação, pois domina a lógica computacional.

Originado a partir da linguagem Logo, a utilização do Scratch no ensino é a aplicação dos conceitos defendidos por Papert. É possível considerar que o Scratch é a matéria na qual Papert se refere para que haja a construção do conhecimento.

Dadas as potencialidades desta ferramenta, surgem possibilidades de aplicações em diversas situações de ensino. Uma delas é no Ensino da Matemática. A partir de então serão elencadas as possibilidades de aplicação deste programa em situações no ensino da matemática.

\section{USO DO SCRATCH NA EDUCAÇÃO MATE- MÁTICA}

(PRENSKY, 2013) afirma que uma das maneiras mais acertadas de resolver problemas em Matemática é por meio da tecnologia, pois alguns programas forçam os alunos a pensar sobre como estruturar o problema e auxiliam nos cálculos, possibilitando aos alunos análises sobre o sentido das respostas.

O Scratch pode ser um aliado importante na Matemática, para que as situações-problemas possam ser exploradas para além da simples obrigação em se chegar à resposta correta.

De acordo com (MARTINS, 2012, p. 47), criar um projeto $S c r a t c h$ requer que se pense numa ideia, que depois se seja capaz de descobrir como dividir o problema em passos menores e concretizá-los, usando os blocos de programação da ferramenta.

Isso torna mais significativo todo o processo que envolve a resolução de problemas, proporcionando ao aluno liberdade nas escolhas e na experimentação pela busca de alternativas, ou seja, o aluno pode realizar tentativas que poderão dar certo ou não, mas ao perceber isso, terá oportunidade de refletir sobre o melhor caminho para atingir o objetivo.

Esse aspecto encontra respaldo nas ideias de $\mathrm{Pa}$ pert, o qual afirma que ao programar o computador, a criança o ensina a pensar, ascendendo na exploração de sua própria forma de pensamento. "Pensar sobre modos de pensar faz a criança tornar-se um episte- 
CONTEÚDOS MATEMÁTICOS: PROPOSTAS COM A APLICAÇÃO DO SCRATCH

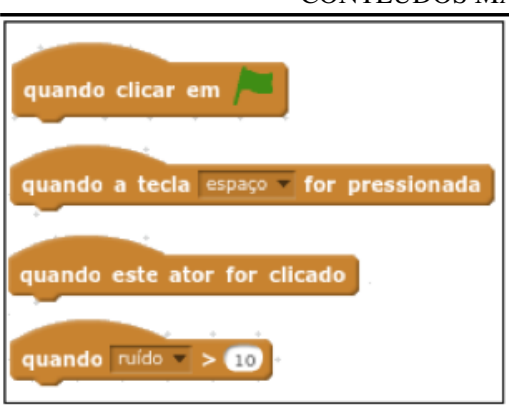

a

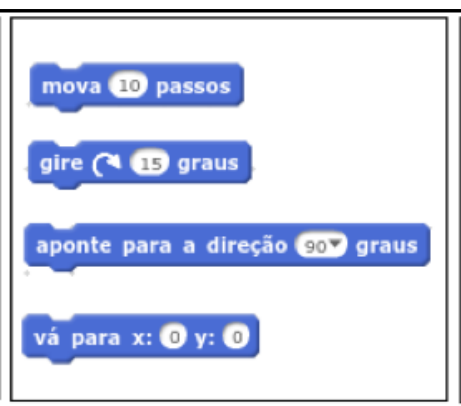

b

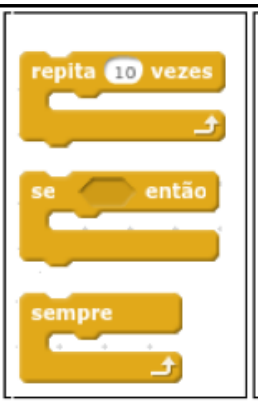

C

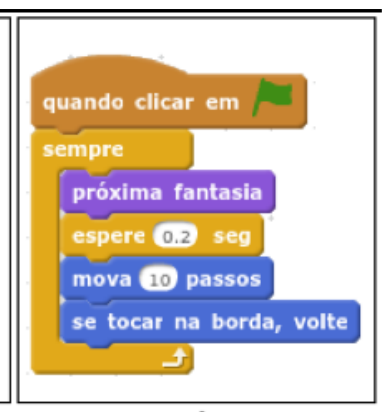

d

Figura 2: Exemplos de Blocos de Construção: a) Eventos; b) Movimento; c) Controle; d) Exemplo de um programa construído com blocos de construção.

Fonte: [SCRATCH] 2017]

mólogo, uma experiência que poucos adultos tiveram" (PAPERT, 1998, p. 35). Esse contato com a linguagem computacional, segundo o autor, pode contribuir para o alcance de níveis de conhecimento complexos, de uma forma natural. Nessa perspectiva, "o computador permite transpor a barreira do pensamento concreto para o abstracto" (PINTO, 2011, p. 35).

É fato que os conceitos matemáticos não podem continuar a ser abordados sem uma participação mais ativa dos alunos. É importante que a eles sejam oportunizadas experiências efetivas no uso desses conceitos. Como afirma Papert, "uma Matemática que seja digna para as crianças não pode ser algo que nós nos damos o direito de impingir-lhes, como um remédio horrível, embora não vejamos nenhuma razão para tomá-lo nós mesmos" (PAPERT, 1998, p. 76).

Destaca-se, portanto, que a posição ativa do aluno na construção de seu conhecimento, tendo no professor um mediador e incentivador nesse processo proporciona que "o aprendiz, constantemente, interprete seu mundo e suas experiências, e essas interpretações ocorrem, inclusive, quando se trata de um fenômeno matemático.”. (MARTINS, 2012, p. 41). Nesse sentido, a visão do estudante sobre a Matemática começa a ser alterada.

Martins (2012) destaca que os "paradigmas computacionais podem influenciar significativamente não apenas o que as pessoas fazem com computadores, mas também a forma como pensam e agem no mundo e dão sentido ao que os rodeia.". Dessa forma, o autor considera que o Scratch é uma das ferramentas "com potencial para desenvolver a fluência tecnológica e ir ainda mais longe à promoção de competências fundamentais para a cidadania no século XXI.

Nessa perspectiva, compreende-se que o uso do Scratch no ensino da Matemática, pode potencializar o desenvolvimento das competências necessárias à resolução de problemas, ao raciocínio lógico e à internalização dos conhecimentos matemáticos. É também uma oportunidade para que os alunos possam vivenciar a lógica de programação.

Dessa forma, nesta seção elencam-se alguns conteúdos matemáticos cujo docente pode explorar com apoio do ambiente Scratch, considerando-se os anos finais do Ensino Fundamental e as Diretrizes Curriculares Estaduais Paranaenses (PARANÁ. 2008).

Os Conteúdos Estruturantes propostos nesse documento compreendem: Números e Álgebra; Grandezas e Medidas; Geometrias; Funções e Tratamento da Informação.

\subsection{Números e Álgebra}

O Conteúdo Estruturante Números e Álgebra compreende os conteúdos:

- conjuntos numéricos e operações;

- equações e inequações;

- polinômios;

- proporcionalidade (PARANÁ, 2008, p. 49).

No que diz respeito às expectativas de ensino e de aprendizagem desse Conteúdo Estruturante, no Ensino Fundamental, almeja-se que os estudantes venham a compreender:

- sistema de numeração decimal e o conceito de notação científica;

- os conceitos da adição, subtração, multiplicação, divisão, potenciação e radiciação de números pertencentes aos conjuntos dos naturais, inteiros, racionais, irracionais e reais e suas propriedades; 
- o conceito de razão e proporção, regra de três, porcentagem, frações e dos números decimais e as suas operações (PARANÁ, 2008, p. 51).

No Ensino Fundamental, é, também necessário uma articulação entre a álgebra e os números, de forma que o aluno:

- compreenda o conceito de incógnita;

- realize a escrita de uma situação problema na linguagem matemática;

- reconheça e resolva equações numéricas e algébricas, inequações, sistemas de equações;

- diferencie e realize operações com monômios, binômios, trinômios e polinômios; equações quadradas, biquadradas e irracionais (PARANÁ 2008, p. 52).

Para estes conteúdos o Scratch proporciona alguns componentes que podem ser utilizados, como o bloco de códigos denominado 'Operadores' (Figura 1 - 1), o qual pode possibilitar comandos específicos para a abordagem dos mesmos. A Figura 3 apresenta o bloco Operadores.

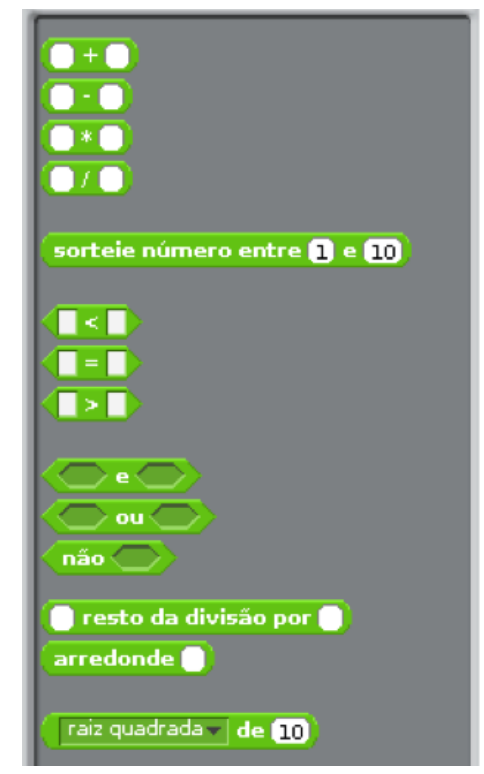

Figura 3: Bloco de código na categoria Operadores Fonte: (SCRATCH 2017)

Nesta categoria existem blocos de comando que podem auxiliar os alunos a aprender a utilizar os números e operadores. Existem os comandos para aritmética simples (soma, subtração, multiplicação e divisão), também os comandos de comparação (maior que, menor que, igual a) e os comandos de lógica (e, ou, não). Outros blocos que fazem cálculos mais específicos como resto, arredondamento e raiz quadrada.

Todos estes blocos dentro da categoria Operadores podem ser ferramentas para o ensino de Números e Álgebra.

\subsection{Grandezas e Medidas}

O Conteúdo Estruturante Grandezas e Medidas apresenta os conteúdos:

- sistema monetário;

- medidas de comprimento;

- medidas de massa;

- medidas de tempo;

- medidas derivadas: áreas e volumes;

- medidas de ângulos;

- medidas de temperatura;

- medidas de velocidade;

- trigonometria: relações métricas no triângulo retângulo e relações trigonométricas nos triângulos (PARANÁ, 2008, p. 53).

No Scratch existem vários blocos que podem ser utilizados no ensino deste conteúdo. A Figura 4 apresenta alguns exemplos.

Algumas medidas como ângulo (Figura 4a), velocidade (Figura 4-b,c) e tempo (Figura 4-d) existem em diversas categorias de código existentes no Scratch. Dentro de situações problema, é possível explorar alguns destes blocos de código para que o aluno exercite e compreenda conceitos de Grandezas e Medidas.

\subsection{Geometrias}

O Conteúdo Estruturante Geometrias se desdobra nos seguintes conteúdos:

- geometria plana;

- geometria espacial;

- geometria analítica;

- noções básicas de geometrias não-euclidianas (PARANÁ, 2008, p. 55). 
CONTEÚDOS MATEMÁTICOS: PROPOSTAS COM A APLICAÇÃO DO SCRATCH

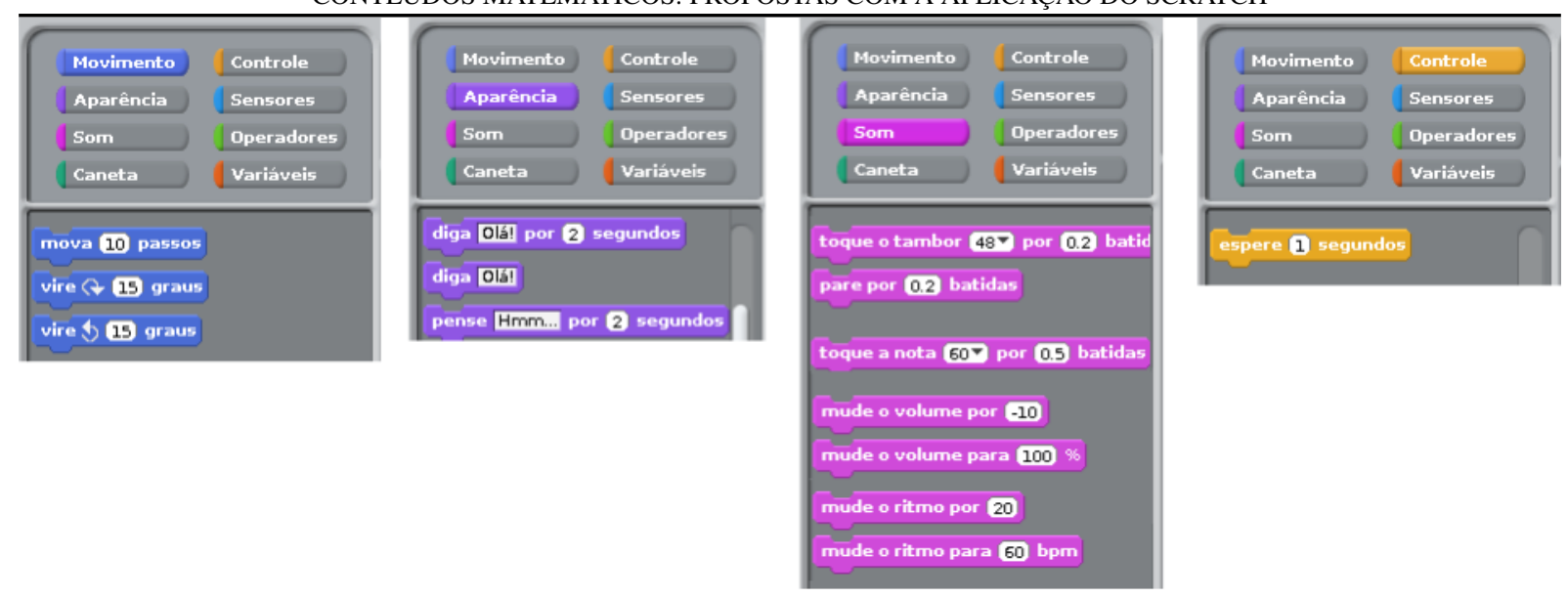

Figura 4: Blocos de código em cada categoria para Grandezas e Medidas.

Fonte: [SCRATCH 2017)

Esse Conteúdo Estruturante tem o espaço como referência, de forma que o estudante consiga analisar e perceber os objetos nele presentes para que, assim, possa representá-los. No Ensino Fundamental, o aluno necessita entender:

- os conceitos da geometria plana: ponto, reta e plano; paralelismo e perpendicularismo; estrutura e dimensões das figuras geométricas planas e seus elementos fundamentais; cálculos geométricos: perímetro e área, diferentes unidades de medidas e suas conversões; representação cartesiana e confecção de gráficos;

- geometria espacial: nomenclatura, estrutura e dimensões dos sólidos geométricos e cálculos de medida de arestas, área das faces, área total e volume de prismas retangulares (paralelepípedo e cubo) e prismas triangulares (base triângulo retângulo), incluindo conversões;

- geometria analítica: noções de geometria analítica utilizando o sistema cartesiano;

- noções de geometrias não-euclidianas: geometria projetiva (pontos de fuga e linhas do horizonte); geometria topológica (conceitos de interior, exterior, fronteira, vizinhança, conexidade, curvas e conjuntos abertos e fechados) e noção de geometria dos fractais (PARANÁ 2008, p. 56).

Para o ensino de Geometria existem diversos blocos que tratam sobre geometria plana, especialmente ao tratar do plano cartesiano. Neste há diversos blocos que apresentam possibilidades de serem trabalhados, especialmente na categoria Movimento. Além dos blocos de movimento, no canto inferior direito do Palco (Figura 1 -3) existe o valor do posicionamento $(x, y)$ que pode auxiliar o estudante a entender os conceitos do plano cartesiano. A Figura 5 apresenta alguns blocos.

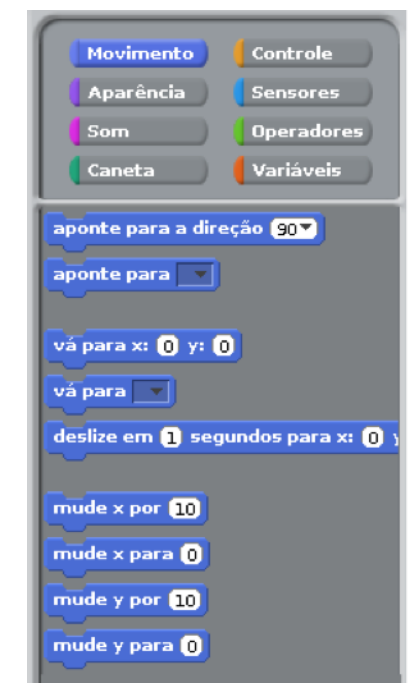

Figura 5: Blocos de Movimento para Geometria. Fonte: (SCRATCH 2017)

Um exemplo claro dessa utilização pode ser verificado no plano de aula proposto por Hartung e Meireles (2011), no qual há atividades que proporcionam a abordagem de conceitos como ângulos, formas geométricas, cálculo de área e perímetro. Como pode ser observado na Figura 6 .

Esse exemplo demonstra que o Scratch traz inúme- 


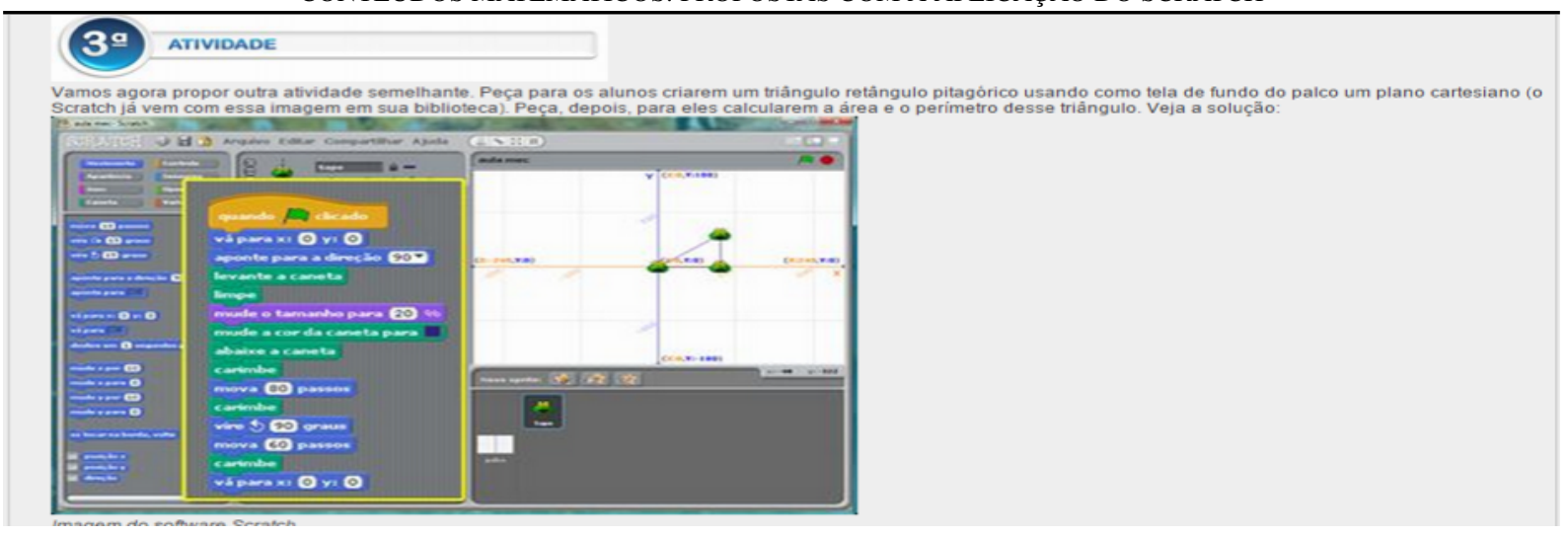

Figura 6: Exemplo de Atividade para Geometria.

Fonte: (HARTUNG; MEIRELES 2011)

ras possibilidades trabalhar com assuntos relacionados à Geometria. Além dessa proposta, outras também podem ser construídas com os alunos.

\subsection{Funções}

O Conteúdo Estruturante Funções para o Ensino Fundamental elenca os conteúdos de função afim e função quadrática (PARANÁ, 2008).

Para esse Conteúdo Estruturante, é importante que o estudante construa conhecimentos acerca da relação de dependência entre duas grandezas. Também é necessário que entenda a relação das funções com a Álgebra.

No Ensino Fundamental o aluno precisa "conhecer as relações entre variável independente e dependente, os valores numéricos de uma função, a representação gráfica das funções afim e quadrática, perceber a diferença entre função crescente e decrescente" (PARANÁ. 2008, p. 59). Sendo que as Diretrizes apontam que uma das formas que podem favorecer essa construção é o uso de situações-problema (PARANÁ. 2008).

Para esses conteúdos os blocos da categoria Movimento podem ser utilizados (Figura 5). Há também no banco de dados alguns jogos que podem ser utilizados para o trabalho com as funções, como é o caso do jogo: Angry Birds no Mundo das Funções Afim e Quadráticas (Figura 7).

\subsection{Tratamento da Informação}

O Conteúdo Estruturante Tratamento da Informação desdobra-se nos conteúdos:

- noções de probabilidade;

- estatística;
- matemática financeira;

- noções de análise combinatória (PARANÁ, 2008. p. 59).

Com esse Conteúdo Estruturante, espera-se que ao final do Ensino Fundamental os alunos conheçam fundamentos básicos da Matemática que lhes possibilitem "ler e interpretar tabelas e gráficos, conhecer dados estatísticos, conhecer a ocorrência de eventos em um universo de possibilidades, cálculos de porcentagem e juros simples" (PARANÁ, 2008, p. 61)

Assim, as Diretrizes orientam que o trabalho deve partir da coleta e organização dos dados em tabelas e gráficos, para posteriormente avançar para "as contagens, os cálculos de média, frequência relativa, frequência acumulada, mediana e moda" (PARANÁ, 2008. p. 61). Nas questões que se referem à probabilidade aponta-se para a necessidade de o aluno "compreender o conceito de eventos, universo de possibilidades e os cálculos dos eventos sobre as possibilidades. A partir dos cálculos, deve ler e interpretá-los, explorando, assim, os significados criados a partir dos mesmos" (PARANÁ, 2008, p. 61).

Para esses conteúdos pode ser explorada a criação de jogos de probabilidade, bem como utilizar o conjunto de comandos Operadores apresentado anteriormente, no qual existe o bloco de código: Sorteie número entre 1 e 100; que pode ser utilizado para auxiliar o ensino de probabilidades.

\section{CONSIDERAÇÕES FINAIS}

É uma tarefa difícil a de atender a nova geração de estudantes em que tecnologias digitais, especialmente as de entretenimento, já fazem parte do seu cotidiano. Mais 


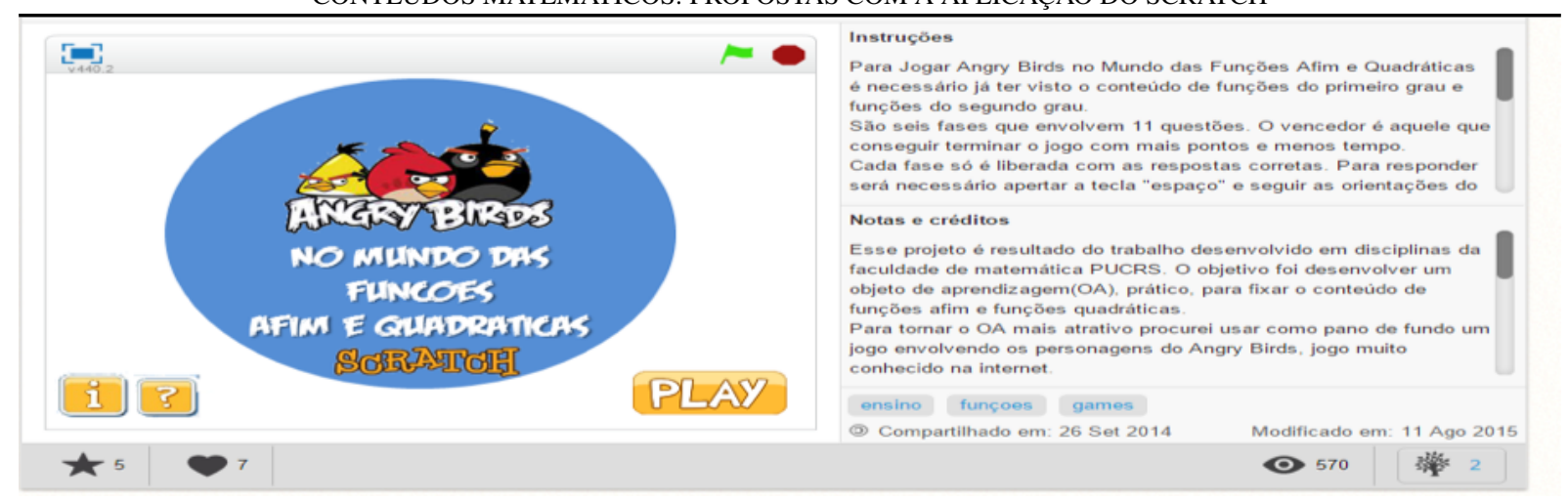

Figura 7: Jogo para o conteúdo Funções. Fonte: (SCRATCH 2017)

difícil ainda é, aos professores, se adaptar a essas novas tecnologias e propor atividades e materiais utilizados pelos alunos durante o aprendizado. Embora as TIC proporcionam ambientes interativos, em que os alunos conseguem permanecer em contato com as tecnologias digitais, deve-se atentar para a finalidade destes ambientes. Isto para que o ensino não permaneça tradicional com um computador.

Para o Ensino da Matemática o Scratch abre novas possibilidades para que as práticas educativas sejam transformadoras, baseando-se na construção do conhecimento pelo aluno.

Ao apresentar a ferramenta Scratch para o ensino da Matemática, é possível evidenciar os conteúdos que podem ser trabalhados por meio dessa ferramenta, bem como perceber que os mesmos podem ser tratados de maneira conjunta evitando uma abordagem desarticulada entre os diferentes conceitos matemáticos.

$\mathrm{Na}$ construção das sequências de comandos com os blocos do Scratch é oportunizado ao aluno a exploração de estruturas algébricas, conteúdos que envolvem números e operações matemáticas, utilização de elementos da geometria analítica e da geometria plana. Tudo isso ao passo em que manipulam, localizam e movem objetos dentro da ferramenta.

Desta forma existem inúmeras possibilidades que podem ser desenvolvidas atividades com o ambiente Scratch no ensino de Matemática. Acredita-se que muitas propostas podem ser construídas por professores e alunos. Para isto é importante que ambos conheçam suas características e potencialidades.

\section{REFERÊNCIAS}

BORBA, M. C.; PENTEADO, M. G. Informática e Educação Matemática. : Editora Autêntica, 2001.
BORBA, M. C.; SILVA, R. S. R.; GADANIDIS, G. Fases das tecnologias digitais em educação matemática: sala de aula em movimento. : Editora Autêntica, 2014.

BRASIL, S. E. F. Parâmetros Curriculares Nacionais: Matemática. : Ministério da Educação, 2001.

HARTUNG, G. E.; MEIRELES, R. Atividades matemáticas com o scratch. In: Portal do Professor. Petrópolis: , 2011.

\section{MARCON, F.; MARTINS, A.; FERREIRA,}

T. K.; SANTOS, M. R.; SANTOS, F. B.; W, R. Potencializando a aprendizagem da lógica com uso de ambiente de programação de alto nível. In: SENID: Seminário de Inclusão Digital. Passo Fundo: , 2012.

MARTINS, A. R. Usando o Scratch para potencializar o pensamento criativo em crianças do ensino fundamental. Dissertação (Mestrado) - Programa de Pós-Graduação em Educação (Universidade de Passo Fundo), Passo Fundo, 2012.

PALHARES, P. Histórias com problemas construídas por futuros professores de matemática. In: Resolução de problemas na formação inicial de professores de Matemática: múltiplos contextos e perspectivas. 1997.

PAPERT, S. A família em rede. Lisboa: Relógio D’água, 1998.

. A máquina das crianças: repensando a escola na era da informática. Tradução de Sandra Costa. Porto Alegre, 2008.

PARANÁ. Diretrizes curriculares da educação básica matemática. Curitiba, PR: Secretaria de Estado da 
Educação do Paraná, Departamento de Educação Básica, 2008.

PINTO, A. S. Scratch na aprendizagem da Matemática no 1. ${ }^{\circ}$ Ciclo do Ensino Básico: estudo de caso na resolução de problemas. Dissertação (Mestrado) - Mestrado em Estudos da Criança. Área de Especialização em Tecnologias de Informação e Comunicação, Universidade do Minho, Portugal, 2011.

PONTE, J. P. O computador na educação Matemática. Lisboa: APM, 1991

PRENSKY, M. Our brains extended. Technology-Rich Learning, v. 70, n. 6, 2013.

ROMANATTO, M. C. Resolução de problemas nas aulas de matemática. Revista Eletrônica de Educação, v. 6, n. 1, Maio 2012.

SCRATCH. Imagine, program, share. 2017. Disponível em: <http://scratch.mit.edu>.

VALENTE, J. Computadores e conhecimento: repensando a educação. : UNICAMP, 1993.

VENTORINI, E. A.; FIOREZE, L. A. O software scratch: uma contribuição para o ensino e a aprendizagem da matemática. In: IV EIEMAT: Escola de Inverno de Educação Matemática. Santa Maria (UFSM): , 2014. 